\title{
Ghosts in a Wilderness: \\ Problems and Priorities of Faculty \\ at Mid-Career and Mid-Life
}

\section{IRENE E. KARPIAK}

The University of Oklahoma

\begin{abstract}
This article explores the experiences of mid-career, older faculty members in higher education through a qualitative study of 20 associate professors ( 15 men and 5 women) between the ages of 41 and 59 at a Canadian university. The study was undertaken to explore how university faculty experience the mid-career and mid-life period in their academic and community work, their personal and family relationships, and their sense of self. The findings focus on a variety of issues revealed in this sample group: the undervalue of teaching as a vocation, noncaring university administrators, rejection in career progression, external personal relationships, impediments to research, failing health, adapting to change, and the question of self-knowledge. While acknowledging several limitations of the study, the perspective of adult development theory points to the potential for greater integration of personality on the part of faculty members, and for its recognition on the part of administrators in fostering a more humanizing, responsive, and caring environment for the
\end{abstract}

This study has been funded in part through a grant from the Centre on Aging, The University of Manitoba. 
conduct of teaching and research. The recognition of significant differences between younger and older faculty, and how the genuine problems facing the latter group may be addressed, will contribute to enhancing the quality of university life generally.

\section{Résumé}

Cet article présente les résultats d'une étude qualitative menée dans une université canadienne auprès de vingt professeurs agrégés (15 hommes et 5 femmes) dont l'âge se situe entre 41 et 59 ans. Cette recherche portait sur ce que vivent les professeurs d'université parvenus au milieu de leur vie et de leur carrière, en ce qui concerne leur travail universitaire et leur engagement communautaire, leurs relations personnelles et familiales et la perception qu'ils on d'eux-mêmes. Les réponses des participants ont permis de dégager diverses préoccupations, dont le peu de valeur accordée à la vocation de l'enseignement, le manque de sensibilité des administrateurs à leurs difficultés, les rejets qui freinent l'avancement professionnel, les relations personnelles à l'extérieur du travail, les obstacles à la recherche, les problèmes de santé, l'adaptation au changement et la question de la connaissance de soi. Bien que cette recherche comporte de nombreuses limites, la perspective de la théorie du développement à l'âge adulte laisse entrevoir la possibilité qu'une meilleure intégration de la personnalité chez les professeurs d'université et la reconnaissance de cette intégration part les administrateurs pourraient contribuer à créer un milieu de vie plus humain et axé sur la personne et ses besoins et, par conséquent, plus propice à l'enseignement et à la recherche. Le fait de reconnaître qu'il existe des différences significatives entre les jeunes professeurs d'université et leurs collègues plus âgés et de savoir comment tenir compte des préoccupations réelles de ces derniers permettront d'améliorer la vie de l'ensemble de la communauté universitaire.

\section{Introduction and Purpose of the Study}

Considerable interest is currently directed toward faculty at Canadian universities. As this group ages, as more faculty are in later stages of their career, and as present economic restraints and rigours increase, questions are being raised concerning an aging, immobile professoriate 
and the related problems of job fulfillment, quality of teaching, scholarship, and productivity (Blackburn \& Lawrence, 1986; Boice, 1986). Universities have attempted to respond to the problem by instituting programs such as early retirement and incentives designed to redirect the 'deadwood' in university departments to other jobs and locations (Boyer, 1991; Fuller \& Evans, 1985). Underlying these initiatives there appears to be an assumption that it is "natural" for middle aged professors to disengage from their disciplines, to stagnate, and to turn their attention to nonacademic activities. Still, we know little about the underlying dynamics of this problem, particularly among Canadian faculty, and their individual experiences. The lack of knowledge of faculty mid-career and midlife development likely substantiates the view that not much happens developmentally to university teachers throughout their lives and careers. This perception in turn may limit faculty initiatives to prepare themselves for this period of life; as well, it may forestall administrators' efforts to deal effectively with the situation in ways other than promoting job relocation and early retirement.

This study was undertaken to explore how university faculty experience the mid-career and mid-life period in their academic and community work, their personal and family relationships, and their sense of self. A qualitative approach was taken because it would permit an "inside," individual view - an appreciation of how individuals perceive, make meaning of, and respond to the circumstances of their life. The major questions behind this research were: a) what happens to university faculty's orientation to their discipline, their research, their teaching, and to their collegial relationships during this period of life and career? b) what sorts of changes do faculty undertake and undergo, and what factors affect these changes?

\section{Theoretical Orientation}

Two major areas of research and corresponding theoretical perspectives provided the background propositions for this study: research on adult development, in general, and on mid-life faculty, in particular, and research on the higher education environment. Concerning adult development, 
among the first to address middle adulthood was Jung. He described the second half of life as a time of astonishing change and personal transformation for many, and while he identified the risks of depression and increased rigidity of this period, he drew attention also to the possibilities for the individual at this time to attain greater integration and balance of personality (Jung, 1954). Jung's observations are supported by other researchers of lifespan development (Fiske \& Chiriboga, 1990; Levinson et. al., 1978; Neugarten \& Gutmann, 1968). Researchers agree that this is a time when issues emerge concerning one's mortality (Jaques, 1965; Tamir, 1989) and the reappraisal of work and relationships (Levinson et al., 1978). More encompassing qualitative changes in the second half of life have also been described with remarkable consistency by researchers. Among these changes are: a) the 'sexual cross-over' - for women it is the tendency toward greater autonomy and instrumentality, while in men the earlier need for achievement and success recedes in favour of a stronger need and capacity for closeness and care (Gutmann, 1975, 1976; Jung, 1966; Levinson et al., 1978; Neugarten \& Gutmann, 1968); b) increasing interiority - greater self-reflection, contemplation, concern with one's inner life, and focus on experience, (Jung, 1969; Levinson et al., 1978; Neugarten, 1968; Neugarten \& Gutmann, 1968); c) the struggle to reconcile opposites within our personality - to find a balance between the polarities of young/old, creation/destruction, masculine/feminine (Jung, 1969; Levinson et al., 1978). Erikson (1969) identified, in addition, the issue of care - individuals' need to determine what it is they care about, care for, and will take care of . Closely related to care is the desire to prepare the next generation to assume its societal role; Erikson (1982) referred to this as 'generativity,' and Levinson et al. (1978), as 'mentoring.' In sum, what emerges is a picture of the mid-life adult male who is more inner directed, more relationship oriented, more care oriented, and more engaged in the effort to find balance and wholeness in his life. A corresponding image emerges for the woman, with the difference residing in her desire to find expression of her inner self through competence and action.

Turning to mid-life faculty, Cytrynbaum's (1982) study of university professors presaged the university's concerns about faculty productivity; their study noted some features of faculty at mid-career: 
Their writing and research may stop, their teaching may be characterized by a lack of enthusiasm or infusion of new ideas, their administrative, counselling and mentoring functions may be left incomplete or inadequately done (p. 13).

Other research on faculty at mid-life have yielded various interpretations of their significance. Some have supported the presence of mid-career unhappiness and malaise (Cafarella et al., 1989; Thoreson, 1984). But Blackburn and Lawrence (1986) conclude, following their longitudinal study, that age is the weakest predictor of performance patterns, while the cohort effect is the strongest. For instance, they suggest that older faculty may actually be publishing at the rate they have always, a rate that is simply lower in comparison to new in-coming faculty. Further, Cafarella et al. (1989) remark upon the overall negative perception of middle-aged faculty and their impact on their institution that is reflected in the research they reviewed. Also, and more importantly, they note that most of this research has been undertaken from an institutional perspective, which focuses on the impact of this age group on the university with respect to research productivity and teaching effectiveness. The individual perspective, on the other hand, which would investigate such themes as change and growth among this group, might yield a different picture of this group. Applying this individual perspective to an exploratory study of 'midcareer senior faculty,' Cafarella et al. (1989) found that these faculty had determined where they would place their energies and time and were doing just that. And, to the extent that the institution valued their activities, both were benefiting. Still, research addressing this perspective is relatively recent and rare.

Research on higher education faculty, in particular the social psychological perspective, provided the second source of propositions for this study. This perspective considers the range of individual, organizational, and environmental factors that contribute to career growth and advancement. Accordingly, career advancement, change, and faculty vitality are conceived to be the product of interactions among individual characteristics and institutional factors. For example, opportunities for career growth and advancement were found to influence the amount of effort employees exert and the degree of work commitment they feel 
(Kanter, 1979). The faculty vitality concept, in particular, was operationalized in research that identified both individual and organizational factors associated with vitality (Clark, Boyer, \& Corcoran, 1985). 'Vital' professors cited such organizational factors as funds, reduced course loads, public recognition, warm relations, and genuine care as those that contributed to their success. Clark and Lewis (1985) concluded that individual and organizational vitality are interrelated, such that individual career vitality is affected by not only personal variables but also organizational strategies and opportunities. They cited institutional values and spirit as factors that incite productivity and creativity, and they advocated for a shared agreement concerning the concept of vitality through power structures that opened career paths and recognized good performance in a variety of ways. These and other studies (Baldwin, 1990) suggest that problems have a larger scope and multiple factors and point to the important role of administrators in career success and faculty renewal.

Emerging from the above is a transactional, interconnected and dynamic image of university life of which one set of factors reflects on mid-life faculty and their qualities, tasks, and concerns and another on the university environment, with its nature and affordances. Casting our lens on the inside, individual perspective would permit an appreciation of the experience of this transaction from the individual faculty member's point of view.

\section{Methodology}

The present study began with a letter of invitation to participate in the study sent to all faculty members at the rank of associate professor $(\mathrm{N}=120)$ in the Faculty of Arts (humanities and social sciences) in a Canadian research university. Fifteen men and five women comprised the sample; all were associate professors between the ages of 41 and 59 . Although most departments, as it turned out, were represented in the sample, no effort had been made to recruit by department. The decision to limit the study to Arts faculty was made in the interests of achieving greater homogeneity of study participants and discipline practices. Associate professors were the focus because they were both at mid-career 
and at the mid-level in professorial rank with the potential for further development and promotion. Related to this group was the question: Why had a significant number of associate professors remained at that rank for so many years without further promotion?

Data were collected by the researcher through personal interviews held on two occasions, conducted by the researcher. All interviews were tape recorded and then transcribed. Two non-directive, interviewing instruments were used. The first was an exercise called "clustering." Clustering is an evocative tool with the capability to generate images, ideas, feelings, and recalled experiences. Originally developed as a technique for creative writing (Rico, 1983) it has been demonstrated to have utility as a data gathering tool for research. Accordingly, individuals were led to cluster around the core phrase, "I, myself at mid-career and mid-life." The points or phrases that each person identified around the core phrase then formed the structure of that person's interview. Each person was asked to address each point in the detail and depth to which he or she desired. Participants then rank ordered each of these points according to their importance. The second part of the interview consisted of an open-ended interview questionnaire that addressed specific questions, for example: "What if any changes have you experienced in the recent past?" "What matters most to you now?"

In the second interview, held within a month of the first, the researcher outlined and elicited comments concerning the major themes emerging from the first interview. Participants' responses to these were recorded and transcribed. Concerning this second interview, participants were offered the option of conducting this one as a focus group interview. Seven male participants agreed to take part in this group meeting which turned out to be a highly interactive, animated, and lively encounter.

The first step of the analysis entailed an examination and comparison of the major points that had been identified and ranked by each participant. These points provided an inventory of the issues these individuals had raised. Then the content of these points, including the amount of attention, time, and emphasis given to each by each respective participant was analyzed. Finally, the key areas of their concentration, the major features, and patterns were identified. A research journal was 
maintained in which reflections, concerns, observations, and emerging patterns were recorded; this provided an audit trail of the analyses. During this process the major themes of individuals' discussions concerning themselves within their respective contexts began to emerge. Later these themes were examined, checked again against the data, and then identified and named.

Before proceeding with the findings, several limitations of this study need to be acknowledged. First, concerning the sample, the group was comprised of only those twenty individuals who, on first invitation, agreed to participate. A second recruitment was not done. So, this group is special in the sense that those in it were so quick to volunteer. Further concerning the sample, as it turned out, most departments of humanities and social sciences were represented. Why those particular one or two people in each department chose to participate is not known. Could they be more adapted (or less) than their non-participating counterparts? Further concerning the sample, being of a qualitative study, it does not claim to be representative of all faculty at this university, nor of faculty in general. However, on this point, when these findings were presented at a recent conference, several in the audience commented that the findings could well have described their own university.

Secondly, concerning the data, the study was carried out in a university context, and all interviews were held at the university. It is not known in what way this context, as well as the researcher's attitude and stance, affected the content of the interview, and in what way it may have influenced what participants chose or chose not to talk about. Further, concerning the data, they provide a slice of life, a still picture of twenty individuals at a particular moment of the day, scholastic term, and season. On this point, one participant commented that on another day he could be saying something quite different. Even between the first and second interviews, spaced a month apart, some had different feelings. And then, within the span of a single interview itself, it was surprising to see the range and movement-from expressions of burn-out and cynicism to hope and optimism. Human beings are complex creatures.

Finally, the nature of this qualitative study is such that it offers an inside, an individual view, as revealed by the participants themselves and 
their experiences and meanings. This contrasts to an outside, institutional view, that may provide readers with statistics, performance data, and objective and observable indicators. Each view, by itself, provides a useful, yet partial picture. The value of qualitative research lies in the extent to which it expands our understanding of the world or some aspect of it (Eisner, 1981). The aim of this study was to expand our awareness and understanding of this group of university faculty from the individual perspective. Readers of this report, depending on their interests, orientations, values, and responsibilities will decide on the usefulness of these study findings for further research, for faculty development, or other administrative decisions, and determine what follow-up, if any, might be worth undertaking.

\section{The Major Themes of the Study Findings}

What follows are the major themes that emerged from the data. These are presented in order of the frequency with which they were identified and discussed by the participants. It should be noted that these themes represent primarily what the study participants chose to talk about in the clustering, non-directive portion of the interview. Further to be noted is the degree to which the themes reflect, not only the individuals in midlife and mid-career, but also the individuals in this period, in transaction with their institution.

\section{Teaching as vocation; but what is its value?}

Joy, gratification, conflicts and tensions characterize these faculty members' experiences of teaching at the university. For some, teaching is clearly a vocation, that which they care most about, within which they view themselves as most productive, and wherein they find their greatest gratification and personal reward. These faculty devote considerable energy to teaching and to student concerns; they derive pleasure and gratification from mentoring students, nurturing them, directing their research, preparing them for careers, and influencing their lives. For others, despite the university's statements to the contrary, teaching is not adequately rewarded. So, faculty struggle with the awareness that their 
primary commitment and care concerns teaching, while believing that teaching is an activity that is undervalued by the university and limiting to their career. Even so, good teaching can lead to teaching awards, and these are highly prized by some faculty who liken achievement of the prize to entering into an exclusive club or inner circle. For some individuals the teaching prize had been a goal towards which they had worked by reflecting on their teaching, learning from evaluations, and adjusting their methods. Finally, teaching awards and good teaching do not go unnoticed by colleagues; those who have a good reputation as a teacher sense that they gain the respect of their colleagues.

While teachers delight in students who are full of hope about their future, they regret recent changes in student life and in academe that have had deleterious effects on their teaching and on the student-teacher relationship. Among these factors are more employed students, larger classes, and increased concerns about sexual harassment. More students employed during the school term means less opportunity to meet outside of class. Students appear to be more tense and more tired. Less hopeful about future career prospects, and less sure about where they are going, some students have become more litigious and consumer oriented, an attitude especially distressing and alien to many faculty.

Sexual harassment is a significant issue for some faculty, insofar as it further distances them from students and in turn diminishes work satisfaction. For those concerned about this issue and the possible risks arising out of student complaints, one response is to become protective of themselves through such actions as distancing themselves emotionally from students, limiting their conversations to matters pertaining only to academic work, and never closing their door when meeting with a student.

Finally, teaching can be a refuge for those faculty who suffer disappointment with regard to denial of promotion, loss of research grants, or frustration of administrative aspirations. It can also be an antidote that offers comfort in facing the anxiety related to ill health and broken relationships.

Faculty facing present financial restraints (in the current academic environment) contemplate ways to renew themselves and to maintain their vitality and interest in teaching. For a few, whatever their efforts 
might be, these do not produce desirable results. In time, a small percentage of faculty face a loss of interest, anxiety, burnout and cynicism. Closely tied to these are feelings of low self-esteem, confusion and selfblame. Among these individuals it is apparent that the process is gradual, painful and seemingly unnoticed by colleagues and administration; second, the situation continues to worsen and extreme solutions like resigning from the university are finally considered; third, an interactional aspect is evident in which the teacher and the students both experience low motivation and exhibit lower productivity. And finally, no one other than the individual him- or herself appears to be aware of or notice the situation, the individual feels and is alone with the problem. Some administrators might describe this individual as 'deadwood,' but they would be overlooking a situation that has been ignored and denied over time, with no efforts to resolve the predicament. As one faculty member offered, "they are not deadwood, they are defeated."

The sense conveyed by this group is that teaching is not valued, nor is it the activity that will gain them recognition and promotion. A not surprising consequence is for some a lessened commitment to the teaching role. Those whose primary interest centers on research have less concern about the low value placed on teaching than those whose primary interest is teaching. But even this former group (though not unequivocally) expressed its support for an enlarged concept of scholarship that would recognize teaching in matters of promotion to full professor.

\section{A university with little interest in our interests}

A prevailing sense expressed by this group of faculty members is that the university administration cares little for them. Administrators are described as invisible, inaccessible 'ghostly figures,' far removed from faculty concerns and seemingly oblivious to faculty's day to day struggles for resources, time, and assistance. While some faculty only observe this situation as regrettable, others are more deeply distressed by it; it affects their view of themselves, of their contribution, and of their sense of the university and its ability to care for itself. The extreme of this sense of isolation from the larger whole is represented by one member who describes himself as 'a ghost,' the individual who, while remaining 
accessible to his students, absents himself as much as possible from departmental affairs. Four areas related to this perceived lack of interest in its faculty on the part of the administration were identified: a sense of feeling unappreciated, unacknowledged and unsupported; the perception that the university administration does not advocate on behalf of faculty to the community; a sense of a lack of collegiality; and an absence of a connectedness to a larger whole.

A most graphic expression of the sense of alienation and loss of the core within the faculty was offered by one faculty member, who voiced his exasperation with an administration overly interested in its external environments and insufficiently concerned with its own faculty. The absence of even "symbolic support" and the perceived dearth of support networks become especially painful in the face of lost and discontinued grants, diminished teaching resources, decreases in services, and disappointments in career progress. The situation becomes even more intolerable when faculty believe that the university now blames them for their predicament, has turned against them, no longer values their contribution, and looks toward their early departure.

Women faculty reveal additional problems to those of feeling unacknowledged and unappreciated. They must cope also with feeling unentitled and unaccepted. And this sense is not limited to their experience with the administration, but often extends to their relationship with departmental male colleagues.

Members have the perception that the administration in its dealings with the community fails to promote its own faculty. In their view the administration does not communicate to the wider community the sorts of endeavours in which faculty, students, and support staff engage, and the awards and recognition that faculty receive. Individuals observe that the administration puts little effort into defending faculty from criticisms lodged by the public and correcting any misconceptions. Perhaps the administration does not intervene on faculty's behalf because in some respects it shares the public's negative perceptions.

Faculty, in general, find the university to be a cold, isolated, fragmented environment; "a wilderness" in which "the human element seems to be missing." Relations between faculty and administration are 
described as non-collegial, ranging from distant and impersonal to warlike and adversarial. Most faculty appear to be cognizant of and sympathetic to the difficulties facing universities in general and the administration in particular. In this regard, while several faculty acknowledge that the present fiscal restraints contribute to the problems that are systemic and beyond the capability of any one individual to solve, they look to the senior administrators to extend themselves in the interests of building collegiality and community.

In contrast to the larger university, the university colleges on campus appear to be the locus for collegiality and connection. There, individuals can and do find support when they are in crisis, a place to enjoy dialogue with others, to celebrate birthdays and important occasions, and to experience an alternative to the impersonality and hugeness of the university.

\section{The "hope" and "despair" of promotion}

The significant feature of this study's participants is that they are all at the level of associate professor. Some are well beyond the normal time at rank (estimated by some to be seven years). Others are moving at an appropriate pace. Most individuals look toward ending their careers on the final step of the ladder at the rank of full professor. For the younger members it is a goal; for the older members it is a symbol of having made it. Some still believe promotion to full professor to be a possibility; others are aware that it would take a great deal of effort, that they would have to do something really substantial, or at least "crank out a few more publications." Still, while hope for a promotion exists, trust in the process does not. Many express doubt and uncertainty in the promotion process; they cannot feel secure about being put forward by their department, nor do they feel safe about putting themselves forward. For some the wounds of previous "rejections" of tenure or "struggle" for promotion are still raw; these are experiences few want to repeat. Rejections can result in a painful sense of isolation from colleagues and department chairs, coupled with an absence of any support network to cushion the blow to their self-esteem and sense of self-worth. 


\section{Love as the engine of survival}

Primary relationships, love interests, long term relationships, marriages that had weathered hard times, grandchildren, extended family - all constitute the emotional glue and are among the ties identified by faculty as those that provide joy, security, support, satisfaction, passion, and pleasure. These ties buffer them against work disappointments and they absorb the energies that professors, disillusioned in their work, redirect to the family. At the same time, the ties of family and family responsibilities siphon off energies that could otherwise be devoted to professional concerns. And finally, when relationships go awry or undergo painful amputations, then grief, depression and suicide are potential effects.

Faculty have continued to come to work, to teach, administrate, serve on committees, carry out research, and prepare and present papers while their internal and personal worlds have been in chaos. Several have struggled with devastating family events and with severe physical and emotional conditions among family members. A number of individuals have been through divorce; some through more than one. In their second marriages they have faced the challenges of living in a blended family, parenting step-children, only to find themselves in some cases once again divorcing.

\section{The researcher - $A$ race horse in a plough harness}

While teaching is the vocation for many of the faculty, research is the primary interest for most of the younger faculty and for nearly all five female participants in the study, irrespective of their age. With an interest in research comes the challenge of juggling its demands with those of administration, teaching, and family. Those engaged in chairing programs and departments feel the most frustrated and torn between their commitment to provide leadership to their programs and their desire to advance their scholarship. Teaching and the relatively high teaching loads are other factors that cut into research.

Family responsibilities also encroach on research. No one illustrates this research/family trade-off better than the female academic who, having established herself early in her career, redirects herself to her family in order to care for her children. While not as frequent now, this experience 
is well-known to the older women faculty who struggle to recover their careers later, knowing full well that they never will. Nevertheless, women in academic life more often continue in their careers as they bear and care for their children. Several people offered suggestions for a system of rewards that acknowledges those who are committed to research. But one individual went even further; he challenged the university to look more deeply into the lives of its faculty, to be sensitive to and understanding of the unique and shared burdens that they carry, and to be willing to accommodate these factors within its reward system.

\section{When health fails: Living urgently under a cloud}

Serious illness such as heart disease, cancer, chronic illness, depression, and changes related to aging are all facts of daily life for many of these mid-career faculty. These conditions impact on their emotional wellbeing, their outlook, and their ability to carry out their work as they once could and still would. These also lend a sense of uncertainty about the future and a race against time to complete projects and maintain responsibilities. Faculty compensate for and accommodate to these conditions. One individual with a chronic illness that limits his mobility schedules his classes in the afternoon, when his body is stronger.

\section{Small changes to forestall big changes}

As described above, some individuals experienced situations such as health problems and marriage dissolution that called for considerable adjustment and change. Notwithstanding, a notable feature of this group is the relative absence of significant changes in their present lives. There is little evidence, especially, of self-initiated change, such as might arise through internal shifts or creative motives, shifts in academic orientation or paradigm, redirection of career and life-style, or alterations in attitude or perspective. To be sure, several have made some shifts, such as refocusing their research and engaging more with community groups through their research. The most evident changes were reported in their approach to teaching (not to be minimized from a growth perspective). But for the most part, many express an attitude of perseverance, of small modifications, with little anticipation of future change. 
Recent literature in higher education suggests that faculty at mid-life are more likely to experience shifts in their orientation to their discipline and to knowledge; they become more interested in interdisciplinary initiatives and in interpretive modes of acquiring knowledge (Boyer, 1991). This sort of shift and reorientation was not apparent among most in this study. Several faculty expressed a hope of being able to relocate to another university but most felt stuck due to their senior positions and pay scales.

The observation concerning change is significant in light of one of the study's original research questions; the question concerned the sorts of changes that individuals were making and the possible supports or obstacles they might be encountering in making these changes. In part, the question arose out of the literature on the mid-life period which drew attention to this period as a time of taking stock, of reappraising one's life and of restructuring some of these areas (Jung, 1954; Levinson et al, 1978). Another study (Fiske, 1980) had reported that the strongest psychological health and mental well-being was found to exist among those individuals who were either anticipating a change or having undergone a recent change. In light of this research, the low incidence of change among this group of university faculty suggests an area worthy of further exploration. Why are faculty resisting initiating changes? What factors contribute to the relatively low incidence of faculty mobility? What supports if any are there for faculty who do initiate or undergo change?

In summary, several of those individuals who had change forced upon them were able now to see the importance of these events to their personal growth. On the other hand, the majority of the others appear to be bypassing the demands for change and making such small changes as to forestall the necessity of making big changes.

\section{Self-knowledge is a dangerous thing}

Some individuals spoke about the processes of reviewing their lives, coming to terms with aspects of their personal histories, and exploring their relationship to self and others, but in general they provided little evidence of engaging in the processes of conscious self-reflection. Faculty rarely referred to their struggles with personal issues and questions of life's meaning. A possible explanation, offered by one study participant is 
that the intellectual capacity, often so high among faculty, is also a useful defense mechanism against one's feelings.

Some individuals are forced through crises to begin the process of self-reflection. One found that through the course of his failed marriage he learned more about himself. Another person described his awareness of getting older, and becoming aware of his mortality. It made him think more about how he was going to use the time left. Would it be devoted to the same thing, working at the same job, or changing and getting into other activities? Another, with a serious chronic illness, described his process of reappraisal and change, and in so doing illustrated also the potential of trauma to transform us to become more compassionate and self-reflective.

In summary, some faculty do engage in self-reflection. Nevertheless, on the basis of the interviews and themes addressed, it would appear that for most of them the "Interior Odyssey," as Neumann (1954) has called it, is not an item of high priority.

\section{Analysis of the Data and Major Themes}

The significance of the major themes may now be considered in light of the framework that includes the qualities of mid-life adults, and the affordances of the university community. Especially notable among the findings are the following: the need of this faculty, especially its older members, for relationship, communion, and community; the sense among faculty that they do not matter to the university; and the importance of the investment they put into the tasks of care and generation. Finally, some observations can be made concerning the problem of some associate professors' extended time in rank, as well as gender and age differences.

\section{The need for relationship, communion and community}

A central theme running through virtually all of the interviews, particularly for those individuals in their fifties, concerns the centrality of relationships, communion and community. The striking feature of these people's dialogue is the importance accorded within the work environment to features normally associated with personal relationships: communication, support, 
affirmation, acceptance, acknowledgment, and collegiality. They seek these qualities with colleagues; are frustrated by their absence within some departments; value them within the college system; miss them with students; and deplore their deficiency in their administrators. Whether the discussions centered on teaching, research, promotion, or university affairs, notable was the extent to which the dialogue touched upon this theme. (A note: The younger participants, those in their $40 \mathrm{~s}$, emphasized different aspects of this theme, primarily the aspects of support in their pursuit of professional goals and an atmosphere conducive to academic work, nonetheless, for the most part they, too, were equally articulate in voicing a desire for a more human quality of work life, and a belief that the administration had a role in bringing this about.)

This finding concerning the importance of relationship, communion, and community challenges a prevailing assumption that academics in higher education are fiercely individual, independent, competitive and solitary (Thoreson, 1984). The present study suggests, rather, that while these qualities may be evident, and perhaps even dominant among some professors, particularly in earlier stages of their career, they do not appear to characterize most of the mid-life members in this study. In this sense, it is possible that mid-life faculty members represent a unique and special population, different from their younger counterparts with respect to their needs, aspirations, motivations, and vulnerabilities. Baldwin and Blackburn (1981) make this same observation, noting that as male faculty become older their need for affiliation increases. To illustrate from the present study, would one expect to hear a young, newly-hired, goal-directed professor express the following sentiment of one 53-year-old participant? "I mean, the flower is not going to bloom if it doesn't get the water, and I don't think we're blooming, because we're not getting the water."

From an adult development perspective, the above findings support mid-life research findings concerning (among men) the stronger need and capacity for closeness and care (Jung, 1954; Gutmann, 1976; Levinson et al., 1978). In the study, particularly among male participants, there is frequent mention of relationship in reference to students, colleagues, and others. It could be posited that the heightened interest in 
teaching evident in many male participants, reported also in other literature, could be related to this increased concern for relationships. It should be noted that the literature suggests that the opposite is the case with female faculty. Their earlier concern for relationship and nurturance now turns toward autonomy and achievement. In the present study, consistent with this apparent change in orientation, most of the women, regardless of their age expressed a strong interest in research and writing with somewhat less enthusiasm for teaching.

\section{The importance of mattering}

A striking feature in the interviews was the extent and pervasiveness of disenchantment, frustration and alienation in varying degrees among many faculty members but most prominently among those over fifty. The sense of not mattering, identified earlier, emerged very early in this study and it surfaced over and over again. First, faculty perceived themselves to be more excluded or marginalized from the operation of the university than they wanted to be, that is, distanced from the university's overall mission, financial concerns, decision making, and future directions. Second, they perceived that the university administration was disinterested in their work and, at worst, was eager to be rid of them. Third, they felt that the administration disregarded their interests and showed little concern for their development, goals, and welfare. Both men and women remarked upon the sense of not mattering. This finding was affirmed by participants during the second interview.

The centrality of mattering, the feeling that the university cares and "gives a damn," is powerfully summarized in a study by Blackburn et al. (1991), who described the relationship between the perception of being cared about to the willingness to fulfill one's teaching role:

In summary ... if I am genuinely interested in teaching and I believe my institution cares, I will give a lot of time to it; if I am not very interested and/or do not believe my institution cares, I will not give a lot of time to it, all of this irrespective of my gender, where I work, what field I am in, how long I have been an academic, what rank I hold, what my specialty is, whether my department or institution supports teaching, or whether my colleagues care (p. 378). 
These researchers are pointing out with respect to teaching that cutting across most if not all other variables is the essential (though not sufficient) requirement for the professor to believe that the university cares (and as interpreted in this study, that, as regards the university, he or she matters).

Mattering was identified by Rosenberg and McCullough (1981) out of their studies of community mental health. It was found to be positively associated with mental health among youth, and speculated to be important also for older adults. Mattering was defined as a feeling that others depend on us, are interested in us, are concerned with our fate, and are affected by our accomplishments and failures. Further, an inverse relationship exists between mattering and marginality; that is, the less one believes one matters, the more marginal one feels. These concepts, mattering and marginality, are useful in the study of university faculty because to the extent that faculty feel that the university does not care and they do not matter, it can be expected that they will also feel marginalized; this was an experience of many of this study.

\section{Attending to the tasks of care and guidance of the next generation}

The issue of care and generation permeates a good part of the study data. It is notable when faculty discuss the concerns of their students, especially the financial and time constraints under which their students operate; it is evident in their concern for fellow faculty, even for those who are not performing along the same lines as they; and it emerges in their discussions of personal relationships with their partners, lovers, children, and grandchildren. (Note that in this section the issue of care relates to the active attitude on the part of faculty toward someone or something. In a previous section the concept of care was associated with the passive attitude, of faculty's experience of being cared for or about, that is, of mattering.)

Erikson (1982) has identified middle adulthood as the stage in which the more prominent issue becomes one of care. Erikson $(1969$, p. 395) states, "in this stage a man and a woman must have defined for themselves what and whom they have come to care for, what they care to do well, and how they plan to take care of what they have started and created." Erikson (1982) goes on to relate care to the task of preparing the 
next generation to assume its societal role (referred to by him as generation and "generativity"). In light of Erikson's view, those faculty whose main interests are teaching and advancing their students can be considered to be doing the essential work of cultivating the next generation of adults. By engaging in these activities of care and generativity they are, it could be argued, demonstrating the active pursuit of the major task of the second half of life.

Taking into account Erikson's observations about care in middle adulthood, it could be further argued that teaching and students, respectively, are what this group has determined to be "what and whom they have come to care for." It is possible that most of the associate professors (particularly those who have been at this rank for an extended period) have determined what is most fulfilling to them, and they are doing precisely what gives meaning to their life, as Cafarella et al. (1989) also found. Within an environment of university care (mattering) they will likely continue with this focus. Without this care (as is currently their perception, and if Blackburn and his colleagues are accurate), they may not. In either case, it is unlikely that they will change. That is, they are not likely to redirect their "care of" from teaching to research.

\section{Associate professors and the extended time in rank}

In the event that readers might assume that academic success had eluded the associate professors in this study, it may be useful to look briefly at their activity level. Eight of the twenty were currently or had previously been department or program heads. At least three had been recipients of one or more university teaching awards. Several had spearheaded academic innovations; some were involved and visible in university-wide committees; and several were active in community affairs, both political and social. Most indicated that they had several unfinished manuscripts in their possession. One was promoted to full professor shortly after the study was completed.

The study sample was constituted of associate professors because this group was identified as having among its ranks a significant number who were at mid-career and who should have been promoted but had not been. The particular problems of associate professors were addressed 
recently by August (1994). He highlighted the often difficult place of associate professors, caught, as if in a sandwich, between assistant and full professors, both of whom often get the greater share of the university's attention. Associate professors, in contrast, are often the forgotten group left to their own resources.

One factor in discussions of promotion concerns the career path that individuals appear to choose, particularly after they receive tenure and the first promotion to rank of associate professor. It would appear from these and other comments that while these individuals initially complied with university expectations regarding teaching and research, following tenure and promotion they struck onto their own path. For some it was the path of research, for a few others, administration; for most in this study, teaching. The dilemma facing these faculty seems to lie in the fact that they have chosen the path that does not offer institutional reward but it does offer personal reward. Given the professional consequences of this situation, a question that could be asked is: Should only the research path be formally rewarded, or should alternative paths be given university consideration? At what cost to students, faculty and the university do the prevailing criteria remain?

\section{Some gender and age differences among the participants}

Significant differences emerged between male and female faculty members, just as they did between older and younger faculty. Concerning the former, the women (of which there were only five) expressed a pervasive sense of not fitting in, not belonging, not feeling accepted, and not feeling entitled, even though most are seasoned faculty members. The image of a novice, impostor, or outsider comes to mind. It could be speculated that family-related career interruptions contribute to this sense of not quite fitting in. Other factors of a systemic nature likely enter as well. Consider, for instance, their reference earlier to not feeling accepted even by their male colleagues.

Notable among the women is a vitality in their work, particularly their research. There is little evidence of arrogance, complacency, stagnation or burnout (although several were often tired) but, on the contrary, of humility and continued striving. They were highly involved in their work 
and strongly committed to research, often in new areas of exploration. The different career trajectories of women, especially their re-engagement with work following an interruption, may actually contribute to the heightened energy and commitment that they bring to their work.

The comments made by women can be interpreted as their unique perspective on the need for a more humane work environment. Notably, regardless of their age, they are in touch with and can articulate the need for care and mattering for themselves and others. Their comments reveal a sensibility that may be just what is needed if the university is to temper its present preoccupation with efficiency, productivity, and accountability with a commitment to care, connection, and community.

Turning to the differences between the individuals in their 40 s and those in their $50 \mathrm{~s}$, it would appear that the younger faculty reflect the strivings and ambitions of younger professionals in general. They want to and expect still to establish themselves as international scholars. They have their goals and they are struggling with conflicting demands of family, teaching, administration, and service. In contrast to the drive for success of the younger members, the faculty members in their $50 \mathrm{~s}$, especially the men, express a different set of motives. Their motives center more on a desire for meaning, for connection, for a sense of shared interests and influence. In a recent chapter on older men, Vaillant (1994) introduced the motive of older men to be "keepers of the meaning." $\mathrm{He}$ referred to the individual's concern with the preservation of the culture in which one lives. Many people in our culture would characterize these motives as lesser, that is, in their being less tied to visible success, productivity, outcomes, and awards. From one perspective, they may even be less useful, less valuable and less desirable to a university struggling with scarce resources and external demands. But, from an alternative adult development perspective, they may have surpassed their earlier motives. Their work inclinations may be expressions of an attitude that is broader, more personal and more integrated. Through their experiences they may have moved beyond what they once were. New priorities have emerged. And their disillusionment and maladjustment may be their response to the lack of fit between their present motives and the institution's mission. 


\section{Humanizing the "Ghosts" and the "Wilderness"}

When asked to consider "What would you want from the University?" the study participants offered suggestions that they believed would contribute to task and work improvement as well as to the emotional and relational aspects of academic life. The following recommendations came up over and over again. In the view of this group, the University should:

a) humanize the institution through more realistic expectations of faculty, and recognition and support of the different efforts and contributions that they bring, e.g., teaching;

b) provide academic support and resources for research, including space to carry out research, and time, through lower teaching loads, reduced administrative duties, and mini-sabbaticals;

c) communicate to the public through the media the valuable contributions of faculty and support staff, and defend its members more vigorously before the public;

d) promote among faculty a sense that they are involved in a joint enterprise, and that they are members of a team;

e) foster an environment in which colleagues stimulate each other's intellectual interests and help each other to develop and grow as intellectuals;

f) develop support networks so that faculty know they are not alone - sponsored networks, informal networks, and services, wherein colleagues can offer support to others;

g) promote greater acceptance of women in the departments;

h) acknowledge the particular circumstances of women faculty, e.g., child bearing and be flexible about the personal demands that women have;

i) help staff fulfill their potential for the last 10 or 15 years of their lives by providing resources, such as career counselling, for people in mid-career; and

j) put into administrative positions the right people who are interested in resolving conflict. 
These recommendations correspond closely to the literature on higher education mentioned earlier, and in particular, to the recommendations arising from Baldwin's (1990) study of faculty vitality. Among his suggestions for increasing faculty vitality were: foster diversified academic careers, including risk-taking and role change; employ flexible personnel policies that are responsive to the unique needs and circumstances of faculty; and recognize and reward professors' achievements.

Finally, reflected in these recommendations is an attitude of care and concern on the part of the participants of this study, not only for themselves, but for other colleagues as well. Evident here is the desire to create a more humane environment in which faculty can feel that they are dealt with fairly and that they matter to others. And underlying these is an apparent assumption that contented faculty will be more productive, more alive, and more able to contribute to the community of teachers, students, and colleagues.

\section{Conclusion}

The study was undertaken from the perspective of adult development out of an interest in the developmental issues of university faculty at midcareer and mid-life. Adult development theory offered a valuable approach for understanding university faculty, its major contribution being in its premise that development, where it is not blocked, continues throughout the life cycle, from birth to death. The direction of this development is toward greater integration, complexity, and inclusiveness of personality. Following from this major premise, older adults have at least the potential to be more integrated, more complex, and more inclusive than their younger colleagues.

The developmental and individual perspective encourages administrators to consider faculty in light of the significant changes that they may undergo throughout the course of their academic career: not merely surface changes such as greater subject knowledge and teaching skills but deeper changes that involve possibly the total personality. Among some, these deeper changes were noted: deeper commitment to students, more attention to the learning process, more effort to create a personal 
and positive learning experience, a greater desire to affect students' lives, and larger concern for relationships in general, including those with colleagues. Even the gripes directed at the university could be seen as an expression of the desire for a more humanizing, responsive, and caring academic environment for themselves and for others.

The value of qualitative research lies in its ability to deepen our appreciation and understanding of a phenomenon or event. Less concerned with generalizability and representativeness, this research aims for usefulness and persuasiveness concerning a state of affairs (Eisner, 1981). It is hoped that the study has persuaded the reader that older faculty are significantly different from their younger counterparts, and changed from the time when they first took their positions on the university campus. Now they have different values, different motives, perspectives, and vulnerabilities. The study participants have offered their observations on the need to transform the "wilderness" into a more humane environment, for drawing out from the margins and into academic life the faculty "ghosts," as well as the administration's "ghostly figures." The extent to which these differences can be acknowledged by the university and incorporated into its system of relationships and rewards may define how this group of faculty continue to contribute (or not) to the quality of university life.

\section{I'm stubborn as those garbage bags \\ that time cannot decay. \\ I'm junk but I'm still holding up \\ that little wild bouquet}

L. Cohen (1993), poet at mid-life

Cohen's lines provide an effective portrayal of this study's faculty. The opposing image of the stubborn, defiant individual who at the same time holds out a bouquet of hope (truce?) fits many individuals in the study. Interspersed within the dialogue of these angry, discouraged, "ghosts" were candid statements of optimism, desire, and hope. They could still envision the possibility of affirmative changes that would 
encourage their reentry into academic life and academic affairs. And they are waiting ...

\section{References}

August, J.R. (1994, Spring). The associate professorship: Motivating faculty members at a poorly defined academic rank, The Department Chair, 10-13.

Baldwin, R.G. (1990). Faculty vitality beyond the research university. Journal of Higher Education, 61 (2), 160-180.

Baldwin, R.G., \& Blackburn, R.T. (1981). The academic career as a developmental process: Implications for higher education. Journal of Higher Education, 52 (6), 598-614.

Blackburn R.T., Lawrence, J.H., Bieber, .P., \& Trautvetter, L. (1991). Faculty at work: Focus on teaching. Research in Higher Education, 32(4), pp. 363-381.

Blackburn, R.T., \& Lawrence, J.H. (1986). Aging and the quality of faculty job performance. Review of Educational Research, 23(3), 265-290.

Boice, R. (1986). Faculty development via field programs for middle-aged, disillusioned faculty. Research in Higher Education, 25(2), 115-35.

Boyer, E. (1991). Scholarship reconsidered: Priorities of the professoriate. The Carnegie Foundation for the Advancement of Teaching Series. Princeton: Princeton University Press.

Cafarella, R.S., Armour, R.A., Fuhmann, B.S., and Wergin, J.F. (1989). Midcareer faculty: Refocusing the perspective. The Review of Higher Education, 12(4), 403-410.

Clark, S.M., \& Lewis, D.R. (1985). Implications for institutional response. In S.M. Clark \& D.R. Lewis, Faculty vitality and institutional productivity, (247-256). New York: Teachers College Press.

Clark, S.M., Boyer, C., \& Corcoran, M. (1985). Faculty and institutional vitality in higher education. In S.M. Clark \& D.R. Lewis, Faculty vitality and institutional productivity, (3-24). New York: Teachers College Press.

Cohen, L. (1993). Stranger music. New York: Random House.

Cytrynbaum, S., Lee, S., \& Wadner, D. (1982). Faculty development through the life course. Journal of Instructional Development, 5, 11-22.

Eisner, E.W. (1981). On the differences between scientific and artistic approaches to qualitative research. Educational Researcher, 10(4), 5-9.

Erikson, E.H. (1969). Ghandi's truth. Magnolia, MA: Peter Smith Publisher Inc. 
Erikson, E.H. (1982). The life cycle completed. New York: W.W. Norton \& Company, 1982.

Fiske, M. (1980). Changing hierarchies of commitment in adulthood. In N.J. Smelser \& E. Erikson (Eds.), Themes of work and love in adulthood. Cambridge, MA: Harvard University Press.

Fiske, M., \& Chiriboga, D. (1990). Change and continuity. San Francisco: Jossey Bass.

Fuller, J.A., \& Evans, F.J. (1985). Recharging intellectual batteries: The challenge of faculty development. Education Record , 66, 31-34.

Gutmann, D. (1975). Parenthood: A key to the comparative psychology of the life cycle. In N. Datan \& L. Ginsberg (Eds.), Life-span developmental psychology. New York: Academic Press.

Gutmann, D. (1976). Individual adaptation of the middle years: developmental issues in the masculine mid-life crisis. Journal of Geriatric Psychiatry, 9, 41-59.

Jaques, E. (1965). Death and the mid-life crisis. International Journal of Psychoanalysis, 46, 502-514.

Jung, C.G. (1954). The development of personality. In Collected works, The development of personality. Princeton: Princeton University Press.

Jung, C.G. (1966). Individuation. In Collected works, Two essays on analytical psychology (Vol 7). Princeton: Princeton University Press.

Jung, C.G. (1969). Stages of life. In Collected works, The structure and dynamics of the psyche (Vol 8). Princeton: Princeton University Press.

Kanter, R.M. (1979). Changing the shape of work: Reform in academe. Current Issues in Higher Education, 1, 3-9.

Levinson, D.J., with Darrow, C.N., Klein, E.B., Levinson, M.H., \& McKee, B. (1978). Seasons of a man's life. New York: Ballantine Books.

Neugarten, B.L. (1968). The awareness of middle-age. In B.L. Neugarten (Ed.), Middle-age and aging. Chicago: University of Chicago Press.

Neugarten, B.L., \& Gutmann, D. (1968). Sociological perspectives of the life cycle. In P.B. Baltes, \& K.W. Schaie, (Eds.), Life-span developmental psychology: personality and socialization. New York: Academic Press.

Neumann, E. (1954). The origins and history of consciousness. Princeton: Princeton University Press.

Rico, G. L. (1983). Writing the natural way. Los Angeles: J. P. Tarcher, Inc.

Rosenberg, M. \& McCullough, B.C. (1981). Mattering: Inferred significance and mental health among adolescents. Research in Community Mental Health, 2, 163-182. 
Tamir, L. (1989). Modern myths about men at midlife: An assessment. In S. Hunter \& M. Sundel (Eds.), Midlife myths: Issues, findings, and practice implications. Newbury Park: Sage Publications.

Thoreson, R.W. (1984). The professor at risk: Alcohol abuse in academe. Journal of Higher Education, 55(1), 56-72.

Vaillant, G.E. (1994). Successful aging and psychosocial well-being. In E.H. Thompson Jr., (Ed.) Older men's lives, 22-41. Thousand Oaks, CA: Sage. 